\title{
ESTUDO GEOFÍSICO DE VAZAMENTO DE COMBUSTÍVEIS EM POSTO DE ABASTECIMENTO
}

\author{
Aline Muriel MENEZES ${ }^{1}$, César Augusto MOREIRA ${ }^{2}$, \\ Lenon Melo ILHA ${ }^{3}$, Camila SCHWEIG ${ }^{4}$
}

\begin{abstract}
(1) Strataimage Consultoria em Geofísica. Praça Floriano, 55, sala 909 - Centro.
CEP 20031-050. Rio de Janeiro, RJ. Endereço eletrônico: aline.menezes@strataimage.com

(2) Departamento de Geologia Aplicada, Instituto de Geociências e Ciências Exatas, Universidade Estadual Paulista / UNESP.

Avenida 24-A, 1515 - Bela Vista. CEP 13506-900. Rio Claro, SP. Endereço eletrônico: moreirac@rc.unesp.br

(3) AFC Geofísica. Avenida França, 1161 - Navegantes. CEP 90230-220. Porto Alegre, RS.

Endereço eletrônico: lmgeofisik@hotmail.com

(4) Pós-graduação em Geologia Regional, Instituto de Geociências e Ciências Exatas, Universidade Estadual Paulista / UNESP. Avenida 24-A, 1515 - Bela Vista. CEP 13506-900. Rio Claro, SP. Endereço eletrônico: camilabarz@hotmail.com
\end{abstract}

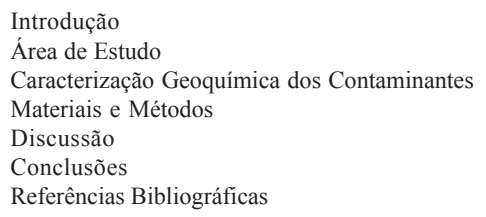

RESUMO - Os métodos geoelétricos têm sido amplamente utilizados em pesquisas que envolvam o processo de avaliação e monitoramento de áreas com risco ambiental. Este trabalho apresenta os resultados da aplicação do método da Eletrorresistividade, através da técnica de caminhamento elétrico para investigar a presença de combustíveis no solo e águas subterrâneas provenientes de um posto de combustíveis, localizado na zona urbana de Caçapava do Sul (RS), sobre solo in situ, produzido por alteração do granito Caçapava. Os resultados sugerem uma associação entre anomalias de baixa resistividade e zonas com combustível degradado proveniente de tanques enterrados inutilizados, sobre a forma de fase livre, atualmente representada como fase residual. Os resultados dos modelos de inversão são condizentes com os padrões esperados para hidrocarbonetos presente na zona saturada do perfil de alteração. O método da Eletrorresistividade demonstrou ser um instrumento importante para avaliação e monitoramento ambiental em conjunto com métodos diretos de investigação.

Palavras-chave: combustíveis, NAPLs, eletrorresistividade, resistividade.

ABSTRACT - A.M. Menezes, C.A. Moreira, L.M. Ilha, C. Schweig - Geophysical study in seepage fuel in station gas. The geoelectrical methods have been widely used in research involving the evaluation and monitoring of areas with environmental risk. This paper presents the results of applying the Electrical Resistivity method by electrical profiling technique to investigate the fuel presence in soil and groundwater proceeding in station gas, located in an urban area Caçapava do Sul (RS), on soil in situ, from modification of Caçapava granite. The results suggest an association between low resistivity anomalies zone with potentially degraded from underground tanks worthless on the form of free phase, now represented as residual phase. The results of the model inversion are consistent with the standards expected for hydrocarbons present in the saturated zone. The electrical resistivity method proved to be an important tool for assessment and environmental monitoring in conjunction with direct methods of investigation.

Keywords: fuel, NAPLs, eletroresistivity, resistivity.

\section{INTRODUÇÃO}

O Brasil possui aproximadamente 35 mil postos de distribuição de combustíveis. No Rio Grande do Sul estão aproximadamente 4 mil e na região de Caçapava do Sul estão concentrados 12 postos, a maioria construída na década de 70 .

Os combustíveis fósseis são constituídos por hidrocarbonetos, sobretudo os compostos BTEX (benzeno, tolueno, etilbenzeno e xileno). A gasolina contém grandes concentrações de BTEX. Estes compostos são classificados quanto à sua densidade como LNAPL (fase líquida não aquosa) caracterizados por serem mais leves que a água, cujas propriedades físicas e químicas os tornam imiscíveis em água.

A gasolina brasileira possui uma característica peculiar, ou seja, apresenta álcool anidro ( $100 \%$ etanol) em sua composição para melhorar o desempenho no motor e reduzir as emissões de poluentes. O álcool foi uma solução brasileira como alternativa ao petróleo e o seu teor presente na gasolina pode variar de 20 a $24 \%$ conforme a Lei Federal $n^{\circ} 10.203$, de 23/02/ 2001(CETESB, 2001). Esta mistura torna a gasolina parcialmente miscível à água. 
Pesquisas levantadas mostram que o vazamento de tanques de armazenamento subterrâneo pode causar a contaminação de solos e águas, podendo contribuir também para o risco de explosões e incêndios.

Segundo Santos (2009) os procedimentos de avaliação de áreas contaminadas por combustíveis envolvem a determinação da extensão, sentido de fluxo e suas concentrações. Vazamentos em postos de combustíveis estão relacionados à deficiência de infraestrutura, manutenção e desgastes dos tanques de armazenamento, que devem ser utilizados por um período máximo de 20 anos.

Grande parte das áreas contaminadas por vazamentos resultam de tanques com avançado estado de oxidação e, em muitos casos, o problema é identificado somente após meses ou anos, seja por contaminação em poços de abastecimento rasos, seja pela contabilidade negativa entre o combustível comprado e vendido.

Diante deste fato, é imprescindível o conhecimento das interações entre os derivados de petróleo e o meio físico em subsuperfície. A residência deste tipo de contaminante altera significativamente os valores naturais dos parâmetros físicos nos materiais geológicos.

Os métodos geofísicos permitem determinar o comportamento dos parâmetros físicos em profundidade de forma unidimensional, bidimensional ou tridimensional, enquanto que abordagem de outras técnicas frequentemente resultam em produtos unidimensionais.

A escolha de métodos elétricos no estudo de áreas potencialmente contaminadas está baseada em diversos trabalhos que demonstram a eficácia destas ferramentas. Diversos trabalhos descrevem a aplicação de métodos geofísicos como uma excelente ferramenta para detectar e monitorar áreas contaminadas por estes compostos em estudos geofísicos por Atekwana et al. (1998), Sauck et al. (1998), Moreira et al. (2006), Braga et al. (2008) entre outros.

Neste trabalho são apresentados os resultados da aplicação do método da Eletrorresistividade, por meio da técnica de caminhamento elétrico, obtidos no estudo da presença de combustíveis em solo e água subterrânea, num posto de combustíveis localizado na cidade de Caçapava do Sul (RS).

\section{ÁREA DE ESTUDO}

A área de estudo está localizada na zona urbana do município de Caçapava do Sul, distante $240 \mathrm{~km}$ de Porto Alegre, acessado a partir da capital através da BR 290 (Figura 1).

A área está associada, segundo Porcher (2000), a corpos plutônicos intrusivos nas unidades meta- mórficas do Domínio Ocidental e que mostram foliações miloníticas, Suíte Granítica de Caçapava do Sul, que compreende dois corpos graníticos intrusivos na Associação Metassedimentar da Sequência Metamórfica Vacacaí.

$\mathrm{O}$ corpo maior, que empresta a denominação à

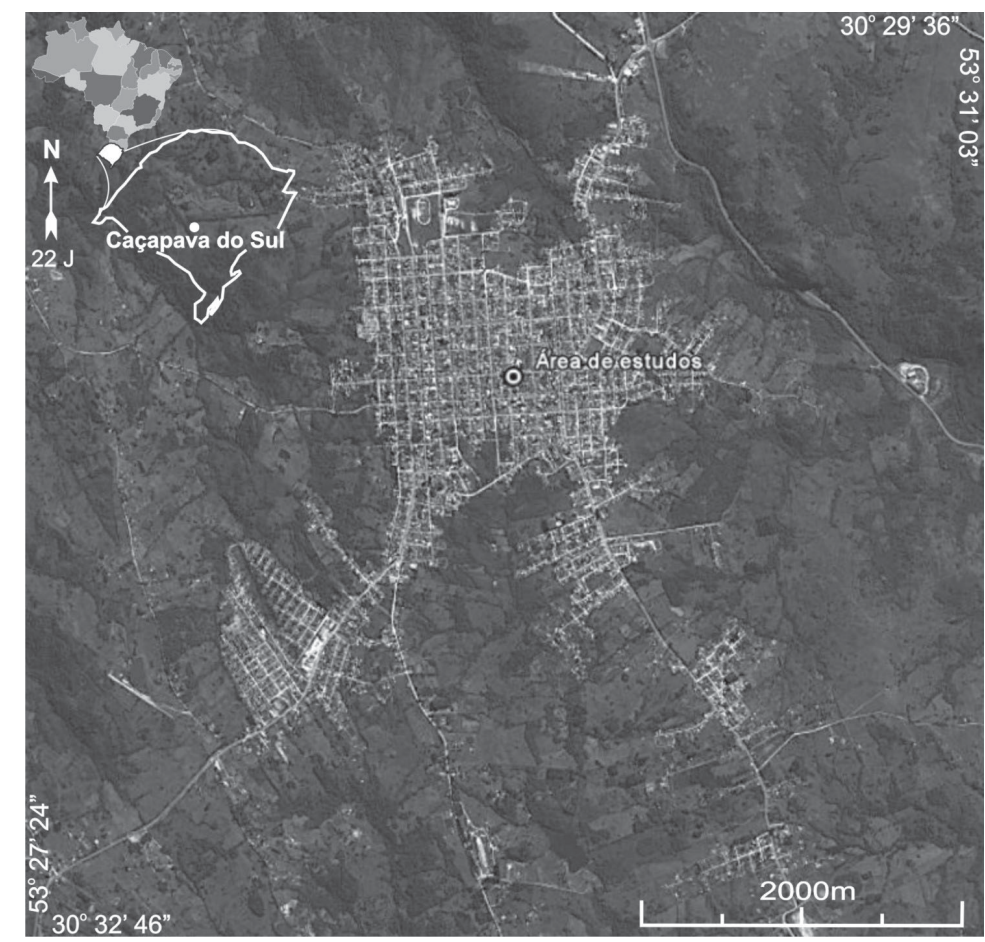

FIGURA 1. Localização da área de estudos (GOOGLE EARTH, 2010). 
suíte, possui uma forma ovulada cujo eixo maior, com cerca de $25 \mathrm{~km}$ de extensão, está orientado segundo uma direção N-S. A Suíte Granítica de Caçapava do Sul é constituída dominantemente de monzo e sienogranitos, com participação subordinada de rochas de composição granodiorítica a tonalítica representadas principalmente na borda oeste do corpo principal. A constituição mineralógica principal está representada por proporções variadas de quartzo, feldspato alcalino e plagioclásio, sendo a biotita o mineral varietal presente nas diversas fácies, enquanto a hornblenda foi identificada apenas nos tipos tonalíticos.
O posto de combustíveis está situado sobre solo residual proveniente da alteração do granito Caçapava. Este solo é caracterizado por granulação argilo-siltosa, subsaturado com muita boa plasticidade, marrom claro. O trabalho de Hansen \& Fensterseifer (2000) classifica este solo como podzólico vermelho-amarelo distrófico e eutrófico, com horizonte A proeminente a moderado.

A área do posto apresenta topografia com declividade no sentido nordeste de aproximadamente 1 grau (Figura 2A). Existem 3 poços de monitoramento instalados na área do posto com nível freático em torno de $2 \mathrm{~m}$ de profundidade (Figura $2 \mathrm{~B}$ ).
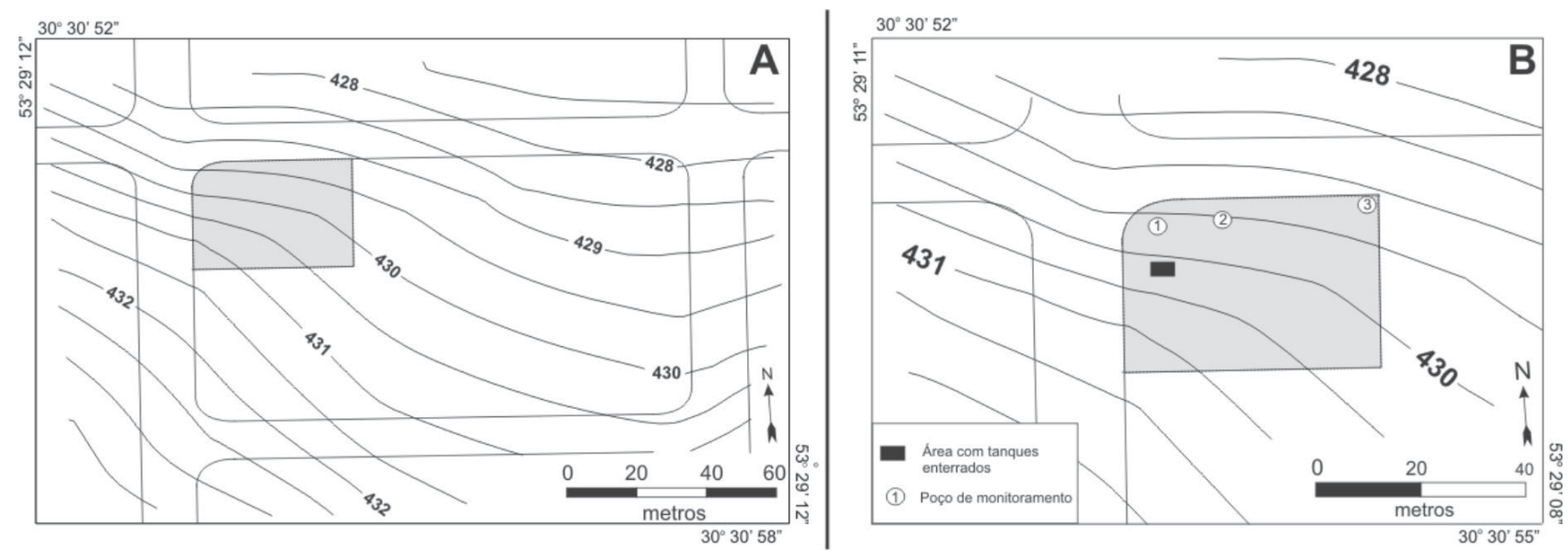

FIGURA 2. A) Área do posto de combustíveis em cinza, com curvas topográficas em metros.

B) Detalhe da área com tanques enterrados e poços de monitoramento.

Apenas o poço $\mathrm{n}^{\circ} 1$ registra a presença de hidrocarbonetos de fase líquida leve não aquosa, flutuantes no nível aquífero (Figura 3). Os poços interceptam o fluxo hidrogeológico, além do fluxo proveniente de uma área com tanques subterrâneos desativados a cerca de 16 anos, mas ainda enterrados na área. A fase contaminante encontrada no poço $\mathrm{n}^{\circ} 1$ aparentemente está relacionada com o vazamento de combustíveis residuais do tanque desativado.

Desta forma, este trabalho realiza uma tentativa de reconhecimento por meio de geofísica, em detectar eventuais combustíveis vazados e presentes no solo, além de objetivar a delimitação aproximada da área de maior abrangência de fluxo dos compostos contaminantes, por meio da interpretação dos dados geofísicos sob a ótica da degradação de hidrocarbonetos e variação temporal do parâmetro físico resistividade elétrica.

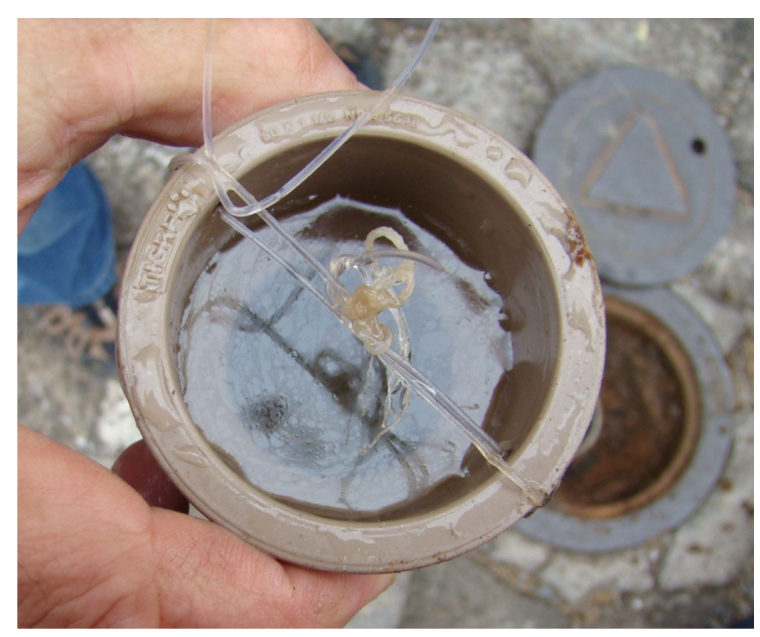

FIGURA 3. Amostra de água proveniente do poço 1, com película irisdecente de combustível sobrenadante.

\section{CARACTERIZAÇÃO GEOQUÍMICA DOS CONTAMINANTES}

Os hidrocarbonetos podem ser denominados compostos de fase líquida não aquosa (NAPLs), cujas diferenças nas propriedades físicas e químicas resultam na imiscibilidade em água (Moreira et al., 2005). De acordo com a densidade, os compostos de fase liquida não aquosa (NAPLs) são classificados 
em 2 classes:

- Compostos de Fase Líquida não Aquosa - LNAPL, caracterizados por serem mais leves que a água. Tais como benzeno, tolueno, etilbenzeno e xileno, constituintes da gasolina, podem ser biodegradados sob condições ambientais.

- Compostos de Fase Líquida Densa não Aquosa DNAPL, estes compostos são caracterizados por serem mais densos que a água.

Deste modo, são necessárias técnicas de investigação para avaliar a extensão da contaminação e os impactos causados ao meio ambiente por estes contaminantes derivados de petróleo.

Isto pode ser esclarecido por meio da correlação do tempo de residência destes contaminantes no solo e tempo de exposição a processos de degradação.

O trabalho de Braga et al. (2008) sugere que a biodegradação dos compostos de fase líquida leve não aquosa - LNAPL pode mudar de forma acentuada as propriedades geoquímicas do aquífero, as quais podem chegar a significativas alterações em medidas de resistividade.

As interações entre o etanol e os compostos BTEX podem resultar num comportamento completamente diferente quanto ao deslocamento da pluma, em relação a gasolina pura. Os três aspectos principais que podem afetar o comportamento dos hidrocarbonetos monoaromáticos benzeno, tolueno, etilbenzeno e xileno em sistemas subsuperficiais em presença de etanol são, segundo Corseuil \& Marins (1997):

- a possibilidade do aumento da solubilidade dos BTEX em água;

- a possibilidade do aumento da mobilidade dos BTEX dissolvidos na água subterrânea;

- a possibilidade de que a presença do etanol possa dificultar a biodegradação natural dos BTEX aumentando a persistência destes compostos na água subterrânea.

\section{MATERIAIS E MÉTODOS}

O método da Eletrorresistividade consiste em empregar uma fonte artificial de corrente ( $I$ ) que é introduzida no solo por meio de eletrodos pontuais (denominados de $A$ e $B$ ). O potencial criado por essa emissão de corrente pode ser medido nas proximidades por meio de eletrodos de medição (denominados $M$ e $N$ ). Com a corrente e os potenciais gerados $(\Delta V)$, é possível calcular a resistividade aparente $\left(\rho_{a}\right)$ Equação (1).

$$
\rho_{a}=K \frac{\Delta V}{I}
$$

onde $K$ é o fator geométrico definido pela geometria dos dipolos $\mathrm{AB}$ e $\mathrm{MN}$ no momento da medida, que é calculado na partir do arranjo geométrico dos eletrodos de transmissão e recepção e define a profundidade de investigação Equação (2).

$$
k=\frac{2 \pi}{\left(\frac{1}{A M}\right)-\left(\frac{1}{A N}\right)-\left(\frac{1}{B M}\right)+\left(\frac{1}{B N}\right)}
$$

O parâmetro resistividade é o inverso da condutividade elétrica, e consiste numa propriedade individual de cada substância, dependente da natureza e estado físico da mesma (Kearey et al., 2002).

Este trabalho aplicou a técnica de caminhamento elétrico, usada para determinar variações verticais de resistividade em duas dimensões (Lowrie, 2007).

A técnica consiste na fixação de eletrodos ou sensores numa linha de aquisição, separados de forma equidistante, utilizados para transmissão e recepção de sinal. O ensaio é desenvolvido com a leitura dos parâmetros para diferentes profundidades e movimentação dos eletrodos apenas num sentido de aquisição, com o arranjo Dipolo-dipolo.

O equipamento utilizado na aquisição de dados foi o resistivímetro Syscal Pro, fabricado pela Íris Instruments (França). Neste trabalho foram realizadas cinco linhas de caminhamento elétrico, com $73 \mathrm{~m}$ de comprimento, dispostas perpendicularmente ao sentido do fluxo, com espaçamento de $3 \mathrm{~m}$ entre eletrodos, com 10 níveis investigação, onde resultaram em uma profundidade máxima de $10 \mathrm{~m}$, sendo também realizadas três linhas perpendiculares às demais (Figura 4).

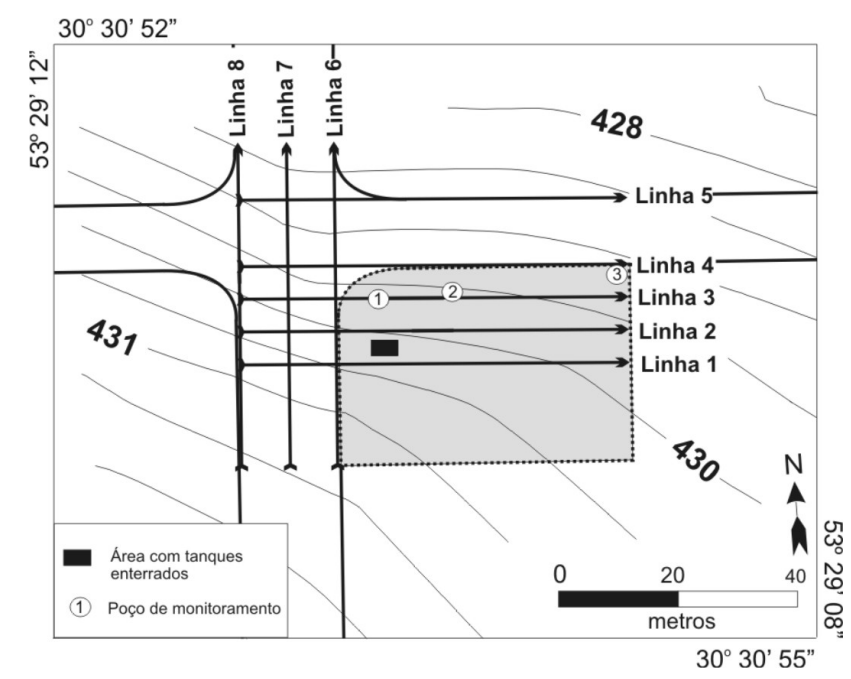

FIGURA 4. Mapa das linhas de caminhamento elétrico. 
Os dados de caminhamento elétrico foram tabelados no programa Surfer versão 8.0, desenvolvido pela Golden software (Estados Unidos), e posteriormente processados no programa Res2dinv, versão 3.4, desenvolvido pela Geotomo Softwares (Malásia).
O Res2dinv é um programa que permite modelos bidimensionais (2-D) para o subsolo, a partir de dados obtidos através de levantamentos elétricos em termos de resistividade e cargabilidade (Griffiths \& Barker, 1993).

\section{DISCUSSÃO}

Os resultados são apresentados sob a forma de modelos de inversão, que consiste numa seção distancia e profundidade, como variação do parâmetro resistividade elétrica variável em escala numérica e de cores (Figuras 3 e 4).

A linha 1 no intervalo entre $0 \mathrm{~m}$ a $12 \mathrm{~m}$ em superfície apresenta valores de baixa resistividade, abaixo de $400 \Omega$.m, representa continuidade lateral e entre 40 $\mathrm{m}$ a $60 \mathrm{~m}$ em superfície também apresenta valores de baixa resistividade. Entre $12 \mathrm{~m}$ e $48 \mathrm{~m}$ ocorrem valores de alta resistividade, acima de $1409 \Omega$.m, associados exposição da rocha sã e a alteração do granito.

Entre o intervalo de $38 \mathrm{~m}$ a $60 \mathrm{~m}$, esta área fica mais espessa provavelmente devido a presença de água proveniente da lavagem de automóveis, infiltrada no calçamento de blocos presentes em todo área do posto (Figura 5). Há uma continuidade desta área nas linhas a montante, contudo menos pronunciadas.

$\mathrm{Na}$ linha 2 ocorre uma anomalia delimitada na seção, com valores inferiores a $114 \Omega$.m, entre $26 \mathrm{~m}$ e $34 \mathrm{~m}$ aproximadamente. $\mathrm{O}$ formato e a intensidade de valores indicam uma área que pode indicar a presença de combustíveis no solo.

Esta área de baixa resistividade é limitada por uma zona de alta resistividade, a partir de $36 \mathrm{~m}$ no sentido do final da seção, com valores acima de $5000 \Omega$.m.

A linha 3 apresenta anomalia de baixa resistividade entre $30 \mathrm{~m}$ e $35 \mathrm{~m}$, com valores inferiores a $400 \Omega$.m. Aparentemente, esta área de baixa resistividade representa uma continuidade lateral de uma área semelhante, descrita na linha 2. Esta hipótese é corroborada pelo fato da linha 3 estar posicionada a juzante da linha 2.

Em semelhança a linha 2, a zona de baixa resistividade também é limitada a por uma zona de alta resistividade. Em ambos os casos, há uma aparente interrupção no fluxo de combustível no solo, possivelmente devido a presença de algum tipo de barreira hidráulica, como matações ou fragmentos pouco alterados do substrato granítico presente da área (Figura 5).

As linhas 4 e 5 apresentam baixos valores de

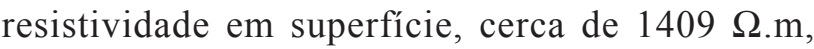
acompanhado pelo aumento crescente de resistividade em profundidade, com valores superiores a $17464 \Omega$.m. Ambas as linhas apresentam uma clara definição litoló- gica da área, ou seja, solo residual sotoposto a uma faixa transitória e posteriormente rocha sã. Não há indícios da presença de combustível em ambas as linhas, pois os menores valores de resistividade são substancialmente mais elevados que os descritos para as linhas 2 e 3 (Figura 5).

As linhas 6, 7 e 8 foram realizadas perpendiculares ao posto de abastecimento, onde o terreno é relativamente mais inclinado, no sentido ao início das linhas (Figura 6).

A linha 6 foi posicionada na lateral anexa ao posto, abaixo e ao longo de uma linha de alta tensão, algo que aparentemente comprometeu a qualidade dos dados, pois ocasionou ruídos e alterações nas medidas.

A linha 7 apresenta uma área de baixa resistividade, com valores próximos de $114 \Omega$.m, com características semelhantes ao descrito para as linhas 2 e 3 . A declividade topográfica neste sentido permite correlacionar ambas as anomalias como proveniente de combustíveis vazados dos tanques enterrados a juzante (Figura 6). A linha 8 também apresenta uma área de baixa resistividade e deve representar o contexto descrito para as linhas com anomalias semelhantes.

A migração de LNAPL em subsuperfície é controlada por chuvas, variações sazonais e pelo gradiente hidrogeológico, associada ao fluxo d'água subterrânea (Daniel et al., 1994).

As zonas de baixa resistividade descritas nas diversas linhas, ocorrência de película de combustível sobrenadante bastante incipiente em amostras de água subterrânea obtidas no poço $n^{\circ} 1$, além da presença de tanques de combustíveis subterrâneos desativados a cerca de 16 anos, são elementos que corroboram com a hipótese de degradação de hidrocarbonetos vazados para o solo e águas subterrâneas.

Estas zonas estão situadas entre $0 \mathrm{~m}$ e $2 \mathrm{~m}$ de profundidade, algo que indica a impregnação do solo por fase residual, acompanhada por fase sobrenadante, conforme constatação em amostras da água subterrânea local.

Os compostos de fase líquida leve não aquosa (LNAPL) tendem a infiltrar no solo por meio da gravidade após a liberação no ambiente, com movimentação lateral na forma de fase livre até atingir a franja capilar. Na ausência de técnicas de remedição artificiais, esses compostos são consumidos na natureza 

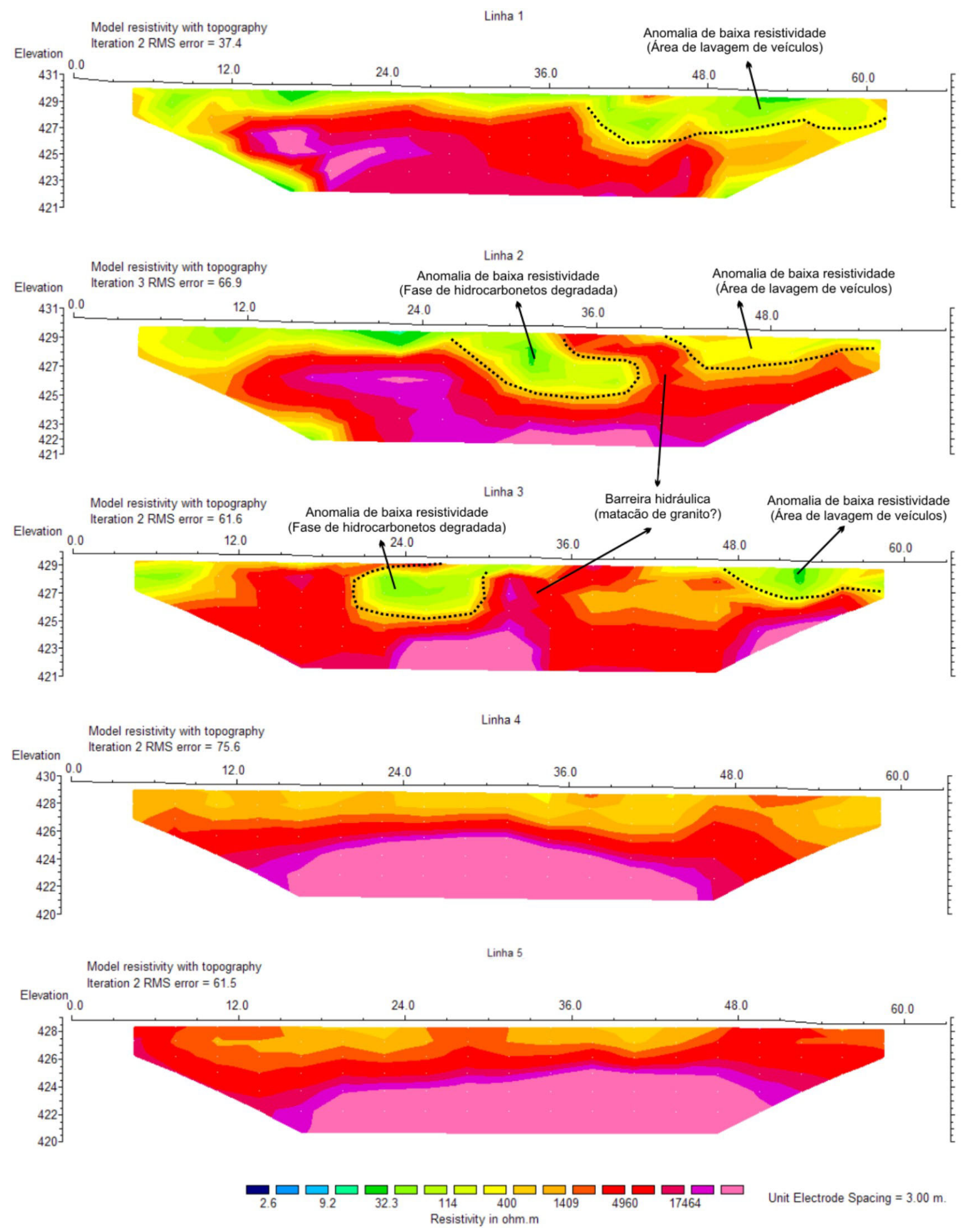

FIGURA 5. Modelo de inversão de resistividade, para as linhas 1, 2, 3, 4 e 5. 

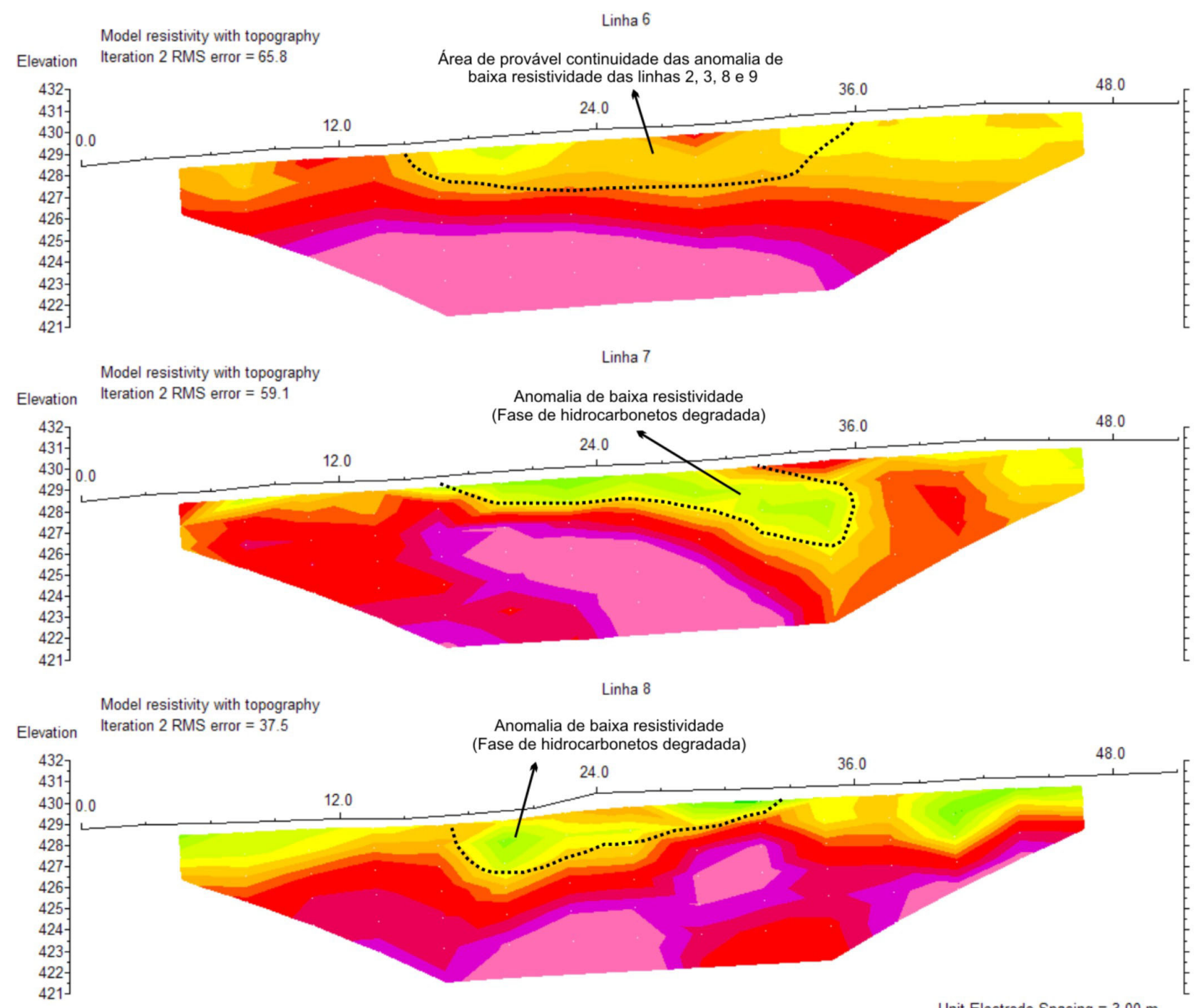

Unit Electrode Spacing $=3.00 \mathrm{~m}$

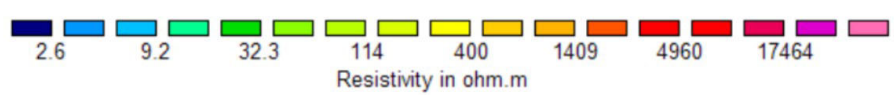

FIGURA 6. Modelo de inversão de resistividade, para as linhas 6, 7 e 8.

por meio de processos de atenuação natural (Moreira et al., 2007).

O fluxo de combustível na área de estudo apresenta movimentação lateral estipulada pela interpolação dos valores anômalos das linhas $2,3,7$ e 8, com ocorrência de valores de baixa resistividade (Figura 7). O aquífero livre é definido pelo contato solo/rocha e aparentemente acompanha a topografia local.

Este fluxo é discordante ao desnível topográfico local, possivelmente devido a presença de fragmentos de rocha parcialmente alterada em solo saprolítico, proveniente do granito sotoposto, que agem como barreiras hidráulicas e ocasionaram o desvio do sentido de fluxo de combustíveis no solo.

A integração das anomalias de baixa resistividade descrita em diversas linhas permite estimar a área de abrangência de combustíveis no solo (Figura 7).

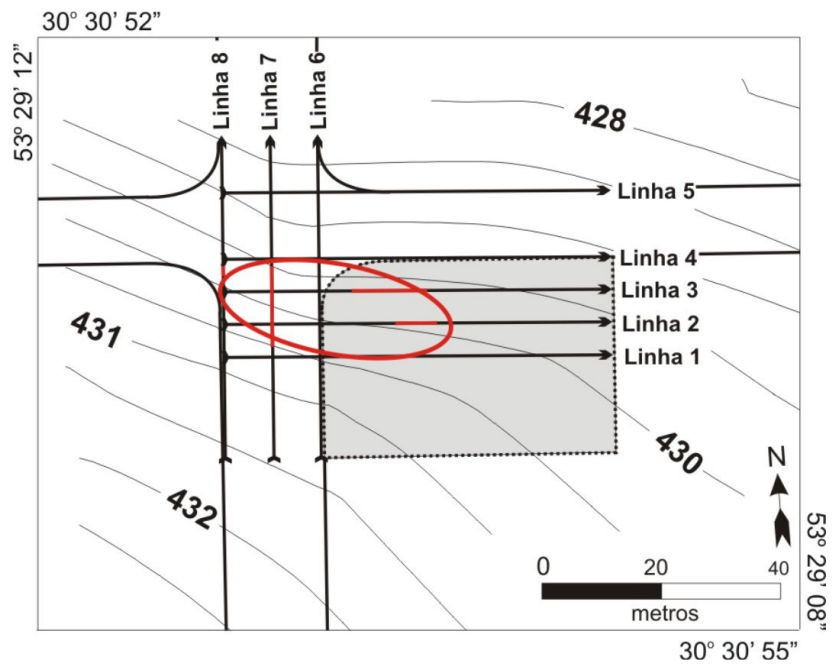

FIGURA 7. Abrangência máxima das anomalias de resistividade em planta. 


\section{CONCLUSÕES}

O trabalho resultou em dados satisfatórios apesar das adversidades, como o trânsito intenso de veículos, além da grande quantidade de ruídos ao método geofísico utilizado.

Entretanto, o fato do posto de combustíveis ser em grande parte revestido por blocos auxiliou na realização das leituras sem grandes percalços. Este tipo de revestimento colabora para a infiltração de água, algo evidenciado por zonas de baixa resistividade na área de lavagem de veículos.

Os dados possibilitaram uma correlação entre áreas de baixa resistividade e a presença de combustível no solo e águas subterrâneas, proveniente de tanques enterrados a montante das anomalias. Análises químicas da água subterrânea atestaram tais apontamentos, embora estejam indisponíveis para incorporação no presente trabalho.

Os resultados dos modelos de inversão são condizentes com os padrões esperados para hidrocarbonetos presente na zona saturada do perfil de alteração. Áreas de baixa resistividade elétrica presen- tes nas primeiras linhas de caminhamento elétrico podem estar relacionadas à degradação na fase residual dos compostos.

O tempo de residência dos contaminantes no solo e o período de exposição dos hidrocarbonetos a processos de degradação influenciam na magnitude de variação do parâmetro físico resistividade elétrica. Tais compostos são caracterizados por alta resistividade num curto período de residência no solo, enquanto que em longo prazo resultam em anomalias de baixa resistividade. Os trabalhos de Braga et al. (2008) e Moreira et al. $(2006 ; 2009)$ advogam neste sentido.

A interpolação do parâmetro de resistividade modelado, obtido nas diversas linhas associadas a áreas com hidrocarboneto degradado, permitiu uma estimativa da área abrangência e do sentido de fluxo de combustíveis no local. Esse sentido é discordante ao desnível topográfico local possivelmente devido à presença de barreiras hidráulicas, como matacões ou blocos de granitos parcialmente alterados, bastante comuns no solo da região de estudos.

\section{AGRADECIMENTOS}

Os autores agradecem aos proprietários do posto de combustíveis pelo acesso a área e aos poços de monitoramento, a Universidade Federal do Pampa, campus de Caçapava do Sul (RS) pelo uso do equipamento geofísico e ao auxílio de todos os envolvidos durante a etapa de aquisição de dados.

\section{REFERÊNCIAS BIBLIOGRÁFICAS}

1. ATEKWANA, E.A.; SAUCK, W.A.; WERKEMA JR, D.D. Investigations of geoelectrical signatures at a hydrocarbon contaminated. Journal of Applied Gephysics, v. 44, p. 167-180, 1998.

2. BRAGA, A.C.O.; MOREIRA, C.A.; CARDINALI, M.T. Variação Temporal da resistividade elétrica em contaminação por gasolina. UNESP. Geociências, v. 27, n. 4, p. 517-525, 2008.

3. CETESB - COMPANHIA DE TECNOLOGIA DE SANEAMENTO AMBIENTAL. Manual de gerenciamento de áreas contaminadas / CETESB. In: SERPA, E.L. \& MARKER, A. (Coords.), 2a. ed. São Paulo, 389 p., 2001.

4. CORSEUIL, H.X. \& MARINS, M.D. Contaminação de águas subterrâneas por derramamentos de gasolina: o problema é grave? Revista de Engenharia Sanitária e Ambiental, v. 2, n. 2, p. 50-54, 1997.

5. DANIEL, J.J.; ROBERTS, R.; VENDI, M. Ground Penetrating Radar for the detection of liquid contaminants. Journal of Applied Geophysics, v. 33, p. 197-207, 1994.

6. GOOGLE EARTH. Versão 4.3 (beta). Europa Technologies - US Department of State Geographer, 2010.

7. GRIFFITHS, D.H. \& BARKER, R. Two-dimensional resistivity imaging and modeling in areas of complex geology. Journal of Applied Geophysics, n. 29, p. 211-226, 1993.
8. HANSEN, M.A.F. \& FENSTERSEIFER, H.C. Caracterização Edafopedológica da Sub-Bacia do Arroio João Dias como Ferramenta de Planejamento Ambiental, Bacia Hidrográfica do Rio Camaquã, RS, Brasil. In: RONCHI, L.H. \& LOBATO, A.O.C. (Orgs.), Minas do Camaquã, um estudo multidisciplinar. São Leopoldo: Editora UNISINOS, v. 1, p. 211-240, 2000.

9. KEAREY, P.; BROOKS, M.; HILL, I. An Introduction to Geophysical Exploration. 3 ed. UK: Blackwell Publishing Company, 262 p., 2002.

10. LOWRIE, W. Fundamentals of Geophysics. Second Edition. New York: Cambridge University Press, 375 p., 2007.

11. MOREIRA, C.A. \& DOURADO, J.C. Análise de contaminantes de fase líquida não aquosa (NAPLs) por aplicação do método Eletromagnético Indutivo (EM). Revista Brasileira de Geofísica, v. 3, n. 23, p. 213-220, 2005.

12. MOREIRA, C.A.; DOURADO, J.C.; BRAGA, A.C.O. Aplicação da técnica de caminhamento elétrico em área contaminada por derivados de petróleo. Revista Brasileira de Geofísica, v. 4, n. 24, p. 1-10, 2006.

13. MOREIRA, C.A.; AQUINO, W.F.; DOURADO, J.C. Aplicação do método eletromagnético indutivo (EM) no monitoramento de contaminantes em superfície. Revista Brasileira de Geofísica, v. 4, n. 25, p. 413-420, 2007. 
14. MOREIRA, C.A. \& BRAGA, A.C.O. Aplicação de métodos geofísicos no monitoramento de área contaminada sob atenuação natural. Engenharia Sanitária e Ambiental, v. 14, n. 2, p. 257-264, 2009.

15. PORCHER, C.A. (Org.). Programa Levantamentos Geológicos Básicos do Brasil. Cachoeira do Sul, Folha SH.22-Y-A. Estado do Rio Grande do Sul. Escala 1:250.000. Brasília: CPRM, 2000.

16. SANTOS, D.A.R. Análise do Monitoramento Ambiental e da delimitação das plumas de contaminantes provenientes de vazamentos em postos de combustíveis: estudos de caso no médio Vale do Paraíba. Guaratinguetá, 2009. 127 p. Dissertação (Mestrado em Engenharia Mecânica) - Universidade Estadual Paulista, Guaratinguetá.

17. SUMNER, J. Principles of induced polarization for geophysical exploration. Amsterdam: Elsevier Scientific, 277 p., 1976.
18. SAUCK, W.A.; ATEKWANA, E.A.; NASH, M. High Conductities Associated with na LNAPL Plume Iaged by Integrated Geophysical Techniques. Department of Geology, Westem Michigan University, Kalamazoo, v. 2, p. 203-212, 1998.

Manuscrito Recebido em: 15 de fevereiro de 2010 Revisado e Aceito em: 16 de junho de 2011 